STUDIA ROMANICA POSNANIENSIA

UAM Vol. 28 Poznaí 2001

JUDYTA WACHOWSKA

\title{
EN TORNO AL GÉNERO LITERARIO DE LA CONFESIÓN
}

\begin{abstract}
A bstract. Wachowska Judyta, En torno al género literario de la confesión [On confession as a literary genre]. Studia Romanica Posnaniensia, Adam Mickicwicz University Press, Poznan, vol. XXVIII: 2001, pp. 177-187, ISBN 83-232-1144-2, ISSN 0137-2475.
\end{abstract}

The present article tries to explain some points of the generic definition of confession, showing that there are some determinant factors that allow to distinguish it from the autobiography such as: thematic space, reason and/or narrataire and treatment of time and memory.

A pesar de que se ha escrito mucho en los últimos años acerca de los géneros autobiográficos, los estudios dedicados a la problemática no han llegado todavía a conseguir despejar todas las densas confusiones que hay entre sus subgéneros. Tal nos parece el caso de la confesión literaria debido por lo menos a un motivo básico. Si históricamente desde las Confesiones de San Agustín el imperativo confesionario se ha constituido como el engendramiento de la forma autobiográfica, la crítica literaria ha conferido el estatuto de género literario propiamente dicho a la autobiografía. Es más, la explicación del término literario de la autobiografía se apoya en la siguiente definición:

(...) la modalidad más cercana a la autobiografía propiamente tal es la llamada confesión, hasta el punto de que podrían considerarse las dos obras más significativas de este subgénero designadas con esta denominación (las Confesiones de San Agustín y las Confesiones de Rousseau), como el inicio y modelo, respectivamente, de esta modalidad narrativa ${ }^{1}$.

Tenemos que ver, por consiguiente, con un equívoco «intercambio» de términos que lejos de aclarar la poética de sus géneros nos introduce en un vasto campo de correlaciones e interdependencias. De otro lado, sin embargo, el adjetivo «autobiográfico» funciona en la crítica bajo doble uso genérico otorgando el nombre tanto a

${ }^{1}$ D. Estébanez Calderón, Diccionario de términos literarios, Alianza Editorial, Madrid 1996, p. 67. 
las manifestaciones de literatura íntima cuyo signo referencial es el propio escritor y, como a una de sus representaciones, quiere decir, a la autobiografía «sensu stricto». Es ahí donde empieza la separación entre un texto confesionario y un texto autobiográfico, ambos siguiendo unos caminos bien distintos a nuestro parecer, no obstante los dos pertenecen a su género mayor.

La clásica ya definición de Philppe Lejeune conferida a la autobiografía:

relato retrospectivo en prosa que una persona real hace de su propia existencia, poniendo énfasis en su vida individual y, en particular, en la historia de su personalidad ${ }^{2}$.

destaca elementos pertenecientes a cuatro categorías: la forma del lenguaje es la narración realizada en prosa, el tema tratado es la vida individual, esto es la historia de una personalidad, la situación del autor presenta su identidad con el narrador del relato y la posición del narrador que se identifica con el personaje principal pero al mismo tiempo emplea la perspectiva de retrospección en su relato. Esa definición, introducida bajo varios juicios críticos, permite aclarar los rasgos esenciales de un texto autobiográfico en perspectiva de sus subgénero vecinos tales como memorias, diarios, autorretratos, poemas y novelas autobiográficos, que no les corresponden entera o parcialmente. Por supuesto debemos estar conscientes de que se trata de proporción o, más bien dicho, de querarquía porque hay zonas de transición muy naturales entre los géneros de la literatura personal que obviamente hacen que su investigador goce de cierta libertad.

No obstante en el caso de la confesión ésta cumple todas de las cuatro categorías lejeunenianas que acabamos de subrayar, con lo cual otra vez tenemos que ver con la coincidencia terminológica. Por eso la inseguridad de llevar a cabo o, al revés, de llegar a una definición estricta consiste en cuestionar ciertas relaciones que salen del ser humano - autor del texto y se exteriorizan entre él mismo y su narrador, y entre él mismo y el protagonista de su discurso. En el caso de la autobiografía al igual que en la confesión, esas relaciones deben transcurrir en la línea unificadora. Pero la pregunta es cómo se puede expresar la identidad del autor con el narrador y con el personaje protagonista teniendo en cuenta que el relato autobiográfico basado en autodiégesis aunque normalmente narrado en primera persona, lo puede estar también en segunda y tercera persona de enunciación. O sea, ¿si casualmente no confundimos la identicidad con el parecido, la imagen del yo con un otro yo-mismo, un doble de mi ser? ¿Cuáles son, o si acaso los hay, los límites de la autoinvención en la autobiografía? Y, por consiguiente, ¿cómo entender la perspectiva de retrospección como empleo de la memoria humana que recupera el tiempo pasado desde la perspectiva del presente narrativo?

Lejeune encontrando un intento de la resolución a esas inquietudes remitió a la idea de que el género autobiográfico es una forma «contractual» que necesita por parte tanto del escritor como de su lector firmar unos pactos gracias a los cuales se

${ }^{2}$ Ph. Lejeune, El pacto autobiográfico, [en] Suplementos anthropos, n”29, Barcclona 1991, p. 48. 
afirma la identidad del contenido de la narración autobiográfica con la firma que su autor inscribe en la página del título - el «pacto autobiográfico» que es como contrato de lectura, y una muestra complementaria de la honestidad del autor que confirma la veracidad de su narración - el «pacto referencial» que cumple las funciones de la verificación de la sinceridad. Pero la referencialidad descubierta por Lejeune no es, a nuestro juicio, una explicación que pueda despejar las preguntas anteriormente hechas sino todo to contrario, subraya efectivamente el hecho de que carecen de repuestas y por eso hace falta pactar.

Si nos dedicamos a un estudio de los dos textos que forman el canon de los escritos íntimos, es decir a las Confesiones de Agustín y a la obra homogénea de Rousseau, notamos inmediatamente que ambos textos tienen su motivo y su narratario, se mueven alrededor de en un espacio temático homogéneo y que además demuestran un trato especial con las categorías de la memoria y del tiempo aunque están muy distanciados en el tiempo, escritos con diferentes objetivos y bajo distintas perspectivas humanas.

El verbo confesar en el caso del santo debe ser entendido en el ámbito clásico y cristiano lo cual nos obliga a explicar por lo menos su doble significado: el de confesar la fe en el sentido del examen de conciencia, hecho que implica obviamente el confesarse de la vida, y el otro es el sinónimo de alabar a Dios, de elogiar al Creador: «Te confieso y alabo, Señor del cielo y de la tierra» ${ }^{3}$. El Dios de su confesión es el motivo y a la vez el fin de su discurso que paralelamente desempeña el papel de] narratario cuya potencia natural garantiza la sinceridad de lo enunciado:

Quiero obrar la verdad en mi corazón, ante ti por esta confesión mía y ante muchos testigos que lean este escrito ${ }^{4}$.

Así pues, Señor, sea yo quien sea, me presento desnudo ante ti. También he declarado lo provechoso que es para mí confesarte. Y hago mi confesión no con palabras y voces del cuerpo, sino con palabras del alma y el clamor del espíritu que penetra tus oídos. (...) Por eso, mi confesión ante ti, Señor, se hace de forma callada y también en voz alta. Mi lengua calla, mi corazón es un clamor 5 .

Es que Agustín sabe que no necesita pronunciar su confesión en voz alta para que Dios se entere de lo que pasa en su corazón, lo hace por tener los testigos humanos en los que además su discurso pueda ejercer una influencia. Todos los treinta y tres años narrados (desde su nacimiento en 354 hasta la muerte de su madre Mónica en 387) se centran en la figura de Dios que le conduce a la conversión al cristianismo (hecho que acontece en el jardín de su casa de Milán y está descrito en el libro octavo) y al mismo tiempo le dota de una memoria que siendo su reflejo engloba la identidad y la continuidad del yo humano. Por tanto podríamos decir que las determinaciones

\footnotetext{
${ }^{3}$ San Agustín, Confesiones, Prólogo, traducción y notas de Pedro Rodríguez Santidrián, Alianza Editorial, Madrid 1999, L. 1. 6, p. 33.

${ }^{4}$ Ibídem, L. X. I, p. 240.

5 Ídem, L. X. l, p. 241.
} 
espacio-temporales de Agustín se encierran en el triángulo: Dios - Tiempo - Memoria. El tiempo viene del futuro, pasa a través del presente y va al pasado, lo medimos en el espacio, porque es una cierta extensión, y este espacio es Dios mismo. De ahí que la memoria verdadera existe en el presente de la enunciación o, dicho de otra manera, opera en el yo de después de la conversión.

Para Rousseau su confesión es como acto humano de justicia. Jean-Jacques, a diferencia del santo no es una persona que públicamente ganó la vida, sino todo al contrario. Está privado de privilegios, de prerrogativas sociales, es un hombre perseguido y decepcionado que a través de su confesión no puede revelar el triunfo de su camino sino presenta el discurso de defensa proclamando su inocencia. Jean Starobinski llama este deseo de ser entendido en Rousseau «transparencia»" ${ }^{6}$, el deseo de hacer su alma transparente, visible y clara para el lector que no sabe percibirlo desde fuera. Para obtener el grado de actualidad, su alma debe ser vista y reconocida por los otros, porque si eso falta, su transparencia se queda solitaria y encubierta. De ahí que el esfuerzo de Rousseau se centra en el grado máximo en presentarse lo más verdadero posible (el problema de la verdad es casi su obsesión) empleando para este fin la «memoria de afectos»:

Sólo me queda un guía fiel con que poder contar: la cadena de sentimientos que han señalado la sucesión de mi ser, y por ellos, la de los acontecimientos que han sido sus causas o sus efectos. Fácilmente olvido mis pesares, mas nunca mis faltas, y menos aún mis buenos sentimientos. Me es harto grato su recuerdo para que se borre de mi corazón. Puedo cometer omisiones en los hechos, transposiciones, errores de fechas, mas no puedo equivocarme acerca de lo que he sentido, no de lo que mis sentimientos me han inducido a ejecutar; y he aquí de lo que se trata principalmente. El verdadero objeto de mis confesiones es hacer comprender exactamente mi interior en todas las situaciones. He prometido la historia de mi alma; y para escribirla con fidelidad no necesito otros recuerdos. Me basta, (...), entrar dentro de mí mismo ${ }^{7}$.

Gracias a la memoria de afectos se puede resucitar el verdadero pasado porque el recuerdo afectivo contiene unas emociones más intensivas. El pasado no se borra en la memoria sino obtiene una dimensión verdadera al ser vivido de nuevo, otra vez. La perspectiva de retrospección le concede a la memoria afectiva la posibilidad de ser vivida en total. En este sentido ya no importan los detalles autobiográficos sino una «leyenda» del corazón cuyo supuesto es descubrir una realidad mucho más importante. «Nous ne sommes plus dans le domaine de la vérité; nous sommes désormais dans celui de l'authenticité »" ${ }^{8}$. La autenticidad a la que Rousseau sigue fiel es la de: vivir es un ir haciéndose en propios sentimientos. No hace falta buscar el verdadero yo en el pasado remoto si no se lo crea en el acto de escribir, no tiene que

\footnotetext{
${ }^{6}$ J. Starobinski, Jean-Jacques Rousseau. La transparence et l'obstacle, Librarie Plon, París 1957.

7 J.-J. Rousseau, Confesiones, Traducción Rafael Urbano, Tebas, Colección Autobiografías y Diarios, Madrid 1978, L. VII, p. 272.

${ }^{8}$ J. Starobinski, op. cit., p. 247.
} 
buscar su verdadera fuente, esa fuente está en el momento presente, en las emociones. El pasado está revivido como un sentimiento actual. «La grande affaire, par conséquent, n'est pas de se penser ni de se juger, mais d'être soì ${ }^{9}$. Ser sí mismo a pesar de todos los obstáculos que le impidan expresarse a sí mismo y le empujen hacia los caminos de reflexión, de vivir en distancia con sí mismo. Es que la distancia no existe, expresar a sí mismo es igual que ser sí mismo. Y por eso no le hace falta el narratario agustiniano, Dios a quien pueda encomendarse, ponerse en sus manos en el acto de escribir. Al componer su discurso se crea de nuevo a sí mismo. Y el juicio final se hará después. Rousseau es extraordinariamente humano en su gesto de llamar la trompeta del juicio final y es al mundo de los sentimientos humanos adonde dirige su discurso. Su narratario es un lector ficticio y Dios aparece sólo como la última instancia ante el cual únicamente puede aparecer otro ser humano diciendo «Yo fui mejor que ese hombre» ${ }^{10}$. O sea, Rousseau necesita absolución de los que han sido la causa de su injusticia, quienes igualmente harán cuenta de sus culpas ante el Ser Supremo.

El significado del verbo confesar proviene del latín confessare derivado de «confiteri» y éste de «fateri», de la raíz de «fari» - hablar ${ }^{11}$. La confesión es revelación, reconocimiento, declaración o manifestación de ideas o sentimientos íntimos y privados, puede ser que por alguna razón antes ocultos, que pueden referirse a la fe religiosa pero no necesariamente, y que tienen que ver en su raíz con la acción de absolución, es decir con exculpa, descarga o reconocimiento de inocencia. Vamos a referirnos primero a la cuestión del tema, que por lo visto, en la confesión es mucho más restringido que en la autobiografía. Así pues, en la autobiografía el tema puede tener la llamada construcción abierta, o sea no hay ninguna obligación de construir un relato marcado estrictamente por algunos momentos o etapas de la vida del autor. El tema autobiográfico aunque fuera sólo por el contenido léxico del término «bios» (la vida) queda, por lo menos hipotéticamente, abierto a un círculo narrativo más amplio: se puede narrar una historia parcial hasta una vida entera. En la confesión el tema es causado y está concentrado en un acontecimiento particular de la vida del autor. Ese evento, a partir de Agustín, suele llamarse «conversión» y es más que nada un momento crucial en la vida, que por sus razones religiosas, morales o intelectuales, la cambia y la concede otro valor. A partir de aquel momento esa vida ya no sigue igual sino concibe su situación transformadora.

La confesión necesita un destinatario o si se lo niega, necesita por lo menos una causa que, creemos, está inscrita en el acto de «pronunciarla». Debe haber un por qué de mostrarse uno sus verdades y puede serlo ora un motivo, ora un alguien considerado como receptor de lo dicho, un narratario real o ficticio. En este sentido el narratario se hace también el motivo de la confesión, concediéndole el espacio temá-

\footnotetext{
${ }^{9}$ Ibídem, p. 248.

10 J.-J. Rousseau, op. cit., L. I, p. 16.

11 M. Moliner, Diccionario de uso del español, Gredos, Madrid 1991, t. I, p. 717.
} 
tico: confesión religiosa, ideológica, sentimental (teológica, mística, litúrgica, jurídica, social) etc. Rosa Chacel en su estudio dedicado a la confesión afirma:

Las confesiones más dramáticas, entre las grandes de la historia, son las que están animadas por el sentimiento de la culpa ${ }^{12}$.

$Y$ añade en adelante:

(...)lo importante en las confesiones no son los hechos relatados $y$, sin embargo, en las grandes confesiones vemos que el secreto conflictivo informa la vida total de cada uno de los hombres cuya confesión escuchamos. Esta relación de conflicto interior y vida real consiste, fundamentalmente, en algo que podríamos Ilamar orientación cualitativa; tendencia, que da tanto a os hechos, como a los no hechos, su color, olor y sabor. Es decir, su cualidad imponderable, pero segura, incanjeable, inconfundible, insustituible ${ }^{13}$.

El carácter del conflicto interior de que sufre el sujeto confesionario es una especie de trazo que muestra su personaje, la "orientación cualitativa», que descubre su figura, lo íntimo de su ser, una especie del orden ético-vital representado por el sujeto gracias a lo cual podemos sentir el peso de la calidad confesionaria.

Otro factor que, según nuestro juicio, conduce la confesión a otros senderos, distintos de los de la autobiografía propiamente dicha, es el del tiempo y la memoria, cuyos aspectos en los escritos personales son de índole importancia. Rosa Chacel se opone a las opiniones tradicionales que defienden la postura del «hacerse» autobiográfico:

La confesión no consiste en revivir ni rehacer; consiste en manifestar lo que nunca se deshizo en el pasado, lo que nunca dejó de vivir por ser consustancial con la vida del que confiesa $^{14}$.

La confesión, subraya Chacel, se refiere a las ideas, verdades o sentimientos que siguen siendo vivos, consustanciales para el sujeto confesionario. Por tanto no es que el que hace una confesión quiera y tenga que revivir o reconstruir su pasado, sino todo lo contrario, no hace falta ninguna reelaboración porque lo que confiesa está presente en él, opera en el presente de su ser. El tiempo pasado es consustancial al presente si la memoria es consciente del pasado, si hay una «permanencia» que crea la inmortalidad de los hechos interiores. Ese pensamiento se inscribe en la línea presentada por James Olney ${ }^{15}$ quien destacó el carácter presente del tiempo autobiográfico apoyándose en el sentido ontológico, del origen griego que denota una acción o un estado continuo apuntando el proceso del ser en progreso. Chacel lo llama «permanencia» pero se trata de la misma cosa: se niega el carácter parcial de la vida para subrayar más bien dicho su totalidad, integridad, cuyo conjunto verídico, uno y único

12 R. Chacel, La confesión, Edhasa, Madrid 1971, p. 17.

13 Ibídem, p. 130.

14 Ibídem, p. 19.

15 J. Olney, Algunas versiones de la memoria / Algunas versiones del «bios»: Ia ontología de la autobiografia, [en] Suplementos anthropos, n"29, Barcelona 1991, pp. 33-47. 
se percibe desde el momento presente. La memoria tiene pues la función del reflejo del presente que resume y sintetiza el proceso de la vida. De un lado representa el descurrir del pasado convirtiéndose en el presente, de otro la unión de ese pasado que se ve retrospectivamente con el presente como el ser ontológico.

María Zambrano en su ensayo teórico dedicado a la teoría de la confesión ${ }^{16}$ dice que este género literario se ha esforzado a llenar el abismo que hay en la filosofía moderna entre la razón (la verdad) y la vida que forma uno de los dramas más grandes de la cultura moderna. En este sentido la confesión es un género de crisis que no se hace necesario cultivar cuando la vida y la verdad están reconciliadas. La crisis es entendida por ella doblemente y se refiere tanto a la falta genérica de una forma que hablase de esa búsqueda, como a la crisis individual del sujeto confesionario que pasando por una etapa de confusión y dispersión - tanto en su situación individual como histórica - va en busca de algo que le «sostenga y aclare» y siente la necesidad de revelarse, de «salir de sí».

Según Zambrano las confesiones muestran un extremo de la existencia subjetiva en el acto de escribir. Es el descubrimiento de quien escribe. La confesión lleva la presencia del hombre real con sus problemas y angustias. El pensamiento existe únicamente como una dimensión dentro de algo más complejo: una situación vital de la se quiere salir. En este sentido la primera confesión, o «preconfesión», explica nuestra autora, es la queja de Job. Pero Job no llega a una verdadera confesión porque no descubre su interioridad, demostrando únicamente su existencia desnuda en el dolor y en la injusticia. Su queja es una apelación directa a la divinidad, pero a la vez reconoce que es en la divinidad donde reside la única salida de su desesperación. Su grito fue escuchado porque él tenía la esperanza de que eso sucediera y $\sin$ ella la queja no se produciría. «Hasta el simple ;ay! cuneta con un interlocutor posible» ${ }^{17}$. El hombre que emprende la confesión está cansado de ser hombre, de sí mismo y por el hecho de confesarse espera su revelación. De ahí que:

Para que una verdad sea asimilada por la vida tiene que verificarse a través de una conversión que le haga aceptar su nacimiento ${ }^{18}$.

Por eso también María Zambrano dice que a Job le faltaban más las razones de la divinidad que explicarían las causas de su sufrimiento que el alivio de sus dolores.

En la confesión se manifiesta también el carácter fragmentario de la vida humana. El hombre se siente como un trozo incompleto, un esbozo de sí mismo y tiene que abrir sus límites gracias a la confesión, necesita salir de sí para completarse:

espera, como el que se queja, ser escuchado; espera que al expresar su tiempo se cierre su figura; adquirir, por fin, la integridad que le falta, su total figura ${ }^{19}$.

${ }^{16}$ M. Zambrano, (1943), La confesión: Género literario, Siruela, Biblioteca de Ensayo, Madrid 1995.

${ }^{17}$ M. Zambrano, op. cit., p. 35.

18 Ibídem, p. 36.

19 Ibídem, p. 37. 
No obstante el darse cuenta de la propia fragmentariedad jamás borra la condición del sujeto, como sucede frecuentemente en las novelas autobiográficas cuyos sujetos ora revelan una cierta complacencia sobre sí ora hacen la operación de objetivación en ese fracaso que transcurre en el tiempo virtual del arte. La confesión, en cambio, se verifica en el tiempo real de la vida:

El que hace la confesión no busca el tiempo del arte, sino algún otro tiempo igualmente real que el suyo. No se conforma con el tiempo virtual del arte. El artista, al crear, remeda la creación divina y crea una eternidad... virtualmente. Es el juego, el juego profundo del $\operatorname{arte}^{20}$.

Analizando las condiciones bajo las cuales acontece la confesión, María Zambrano se refiere primero a la obra de San Agustín subrayando que lo que constituye propiamente su confesión es ofrecerse a la mirada divina, entrar en la luz, hacerse visto y mostrarse abiertamente. No se trata de ser visto, ya que para una persona creyente está claro que Dios la ve constantemente en todos los actos de la vida, sino ofrecerse a la vista. Por eso la confesión no está justificada por la sinceridad, sino por el acto de ofrecerse íntegramente a la mirada divina. Este ser visto significa descubrirse a sí mismo, ser transparente. La confesión en su sentido exacto tiene lugar en el instante mismo en que alguien se descubre. Y cuando se muestra a la luz, su vida ya en este momento comienza a aclararse y no tiene que contar sus culpas ya. San Agustín quiere hacerse transparente también a los hombres, quiere mostrares lo que es, quiere mostrar el hombre nuevo «recién nacido» de él, su Dios y su verdad encontrada. Con esta acción rompe el hermetismo, la congoja humana, y realiza un intento de comprensión entre sus semejantes, dotándoles del crédito de confianza.

(...) porque si en la confesión se parte de la soledad, se termina siempre como San Agustín en comunidad. La verdad es compartida siempre ${ }^{21}$.

La acción precipitada sin ser transparente para el hermano, sin contar con su caridad, por puro que sea en su origen, desata la violencia y el crimen, la guerra cainita ${ }^{22}$.

Agustín a través de su confesión ha vencido el terror del nacimiento, el temor a la muerte y la confusión de la injusticia entre los seres humanos. Gracias a ello su vida se le hizo posible. El fruto de su confesión es la «evidencia», algo que en mística se llama revelación, explica Zambrano, o dicho de otra manera, el punto en que se tocan la verdad de la razón y la verdad de la vida, revelación de la realidad. La evidencia presenta un redescubrimiento:

No es una verdad nueva, sino una forma que toma algo que ya se sabía, y que ahora penetra en la vida modelándola; es algo que antes no operaba y que ahora se ha vuelto operante $^{23}$.

\footnotetext{
${ }^{20}$ Ídem, p. 27.

21 Ídem, p. 56.

22 Ibídem, p. 57

${ }^{23}$ Ibídem, p. 69.
} 
Aparece como su logro intelectual y ejerce una transformación en el conocimiento abriéndole paso a la confianza.

Lo que le sucedió a Jean-Jaques Rousseau, a la vista de nuestra autora, es la soledad que tiene sus raíces en el «cogito» cartesiano que abre el espacio a la conciencia. La conciencia está siempre en el fondo de toda justificación del yo. La soledad deja de ser sólo el punto de partida, como en el caso de Agustín, sino se convierte en el punto de llegada.

Toda realidad, todo objeto o pretensión de objeto, habría de ir a buscar su última justificación en una inmediatez de su conciencia. Actos de conciencia y en su centro último, como unidad última e interior, el yo, el yo en soledad ${ }^{24}$.

El mundo y sus riquezas quedan sujetados a la medida humana. La razón queda librada de la vida y se quediı libre. El hombre y su conocimiento, su unidad queda rota, se vive "por y en conocimiento, como si el conocer fuese enteramente, y sin más, existir ${ }^{25}$. De otro lado, el hombre con su corazón se sentía sólo, abandonado por la mente seguía vivo, sentía, amaba y tenía esperanzas.

La originalidad del corazón, la originalidad del individuo, bien pronto se haría visible de modo análogo al de la mente. El individuo, en sus pobres y obscuras entrañas; sus misteriosos cuartos abandonados cuanto más llenos, se manifestarán en su originalidad; originalidad que vale tanto como espontaneidad, pues las dos cosas se identificaron. Lo espontáneo, las entrañas dolidas y abotagadas, la vida en su dispersión y obscuridad, fue lo original, es decir, el ser, la realidad válida, la que en su supremacía no necesita transformarse, tan sólo rebelarse, manifestarse, reclamar sus derechos ${ }^{26}$.

Así nació la confesión de Jean-Jaques, dice María Zambrano, quien la hace con su terrible inocencia sin ganar nada en el acto de humildad. Le mueve la creencia de que su historia es la realidad de su corazón y la creencia en la naturalidad del ser humano. Esa doble fe «es su teoría original de que el hombre nace libre y dondequiera se encuentra encadenado» ${ }^{27}$. Su corazón está abandonado y a la vez independiente, vuelto hacia sí mismo, y no encuentra ningún lugar que lo contenga. Es un corazón solitario que a manera de espejo quiere devolverse su propia figura con toda sinceridad, honestidad, «un alma arrojada a la voracidad de los hombres» ${ }^{28}$ que además goza de su imagen.

Rousseau nos revela ese funcionamiento, que no podía por menos de expresarse. Por dos motivos: porque la característica de esta vida del corazón va a ser la expresión, vida a la que la expresión hace real y que en la expresión se cumple como si ella fuese su término.

\footnotetext{
24 Ibídem, p. 70-71.

25 Ibidem, p. 75.

26 M. Zambrano, op. cit., p. 76.

27 Ibídem, p. 80.

28 Ibidem, p. 77
} 
Y todavía más, porque siendo el primero en sentirlo, no podía por menos que apresurarse a comunicar al inundo todo tan grata nueva ${ }^{29}$.

María Zambrano ve el error de Jean-Jaques en falta de la trascendencia de su verdad que, tal como lo hemos subrayado ya, encuentra sus relaciones en el mundo humano. Por eso dice que Rousseau no gana nada a través de su confesión, sino se queda enormemente solitario. Tal es su condición humana, su tiempo su epigonismo romántico...

Como ya hemos dicho, uno de los aspectos que segura y fuertemente distingue la confesión de la autobiografía es el valor ejemplar concedido a la personalidad contada en la confesión causado por su evolución, cambio intelectual, moral o, dicho de otra manera, «conversión». Ese cambio es la causa y el motivo de la narración confesionaria que fluye recogiendo el tiempo desde la perspectiva actual en que el sujeto que se describe ya había juntado sus aspectos huidizos, ya se había cumplido en algún que otro sentido. Por lo pronto no tiene que realizarse a través de su relato, sino está en otro momento, había dado ya un paso adelante y a través del relato simplemente quiere confesar lo suyo, expresar o manifestar lo que encontró después de su «conversión» y compartirlo con alguien. Bajo esta perspectiva nos parece que la confesión está guiada por otras razones que la autobiografía, distintos fundamentos que conducen finalmente a otro fin. Desde luego la transformación puede vestir distintas «máscaras», no obstante es el punto de inicio en el acto confesionario. Luego la expresión de lo sucedido es ya otra cuestión, otra calidad. Pero lo importante es que no hace falta en el acto de escribir esa reconstrucción o desciframiento de la vida en su conjunto o «segunda lectura de sí mismo», como dice Georges Gusdorf ${ }^{\text {(*) }}$, por el simple hecho de que ese objetivo ya se había cumplido gracias a la conversión. Al crear la narración confesionaria, su autor quiere «revivirse» sólo en el sentido de presentarse vivo ante los ojos de sus lectores, mostrarse auténtico, verdadero y fidedigno, tal como sucede en la realidad objetiva. Por eso la Confesión de San Agustín es profundamente mística y la de Jean-Jacques es abiertamente sensacionista, pero ambas son unos manifiestos impresionantes que revelan un fragmento decisivo de sus vidas. El mismo acto de la extrema sinceridad, posición clara y abierta de presentarse «desnudo», según las palabras de Zambrano, constituye ya la verdadera confesión. Y la confesión verdadera se realiza, hasta logra su fin, en el momento en que se emprende el relato de nuestro ayer, cuando el sujeto confesante se revela abiertamente. Por eso también, sostiene la filósofa española, no hace falta que el sujeto cuente sus culpas porque no es la sinceridad que justifica su confesión sino el puro acto de ofrecerse a ser visto, de descubrirse enteramente.

\footnotetext{
${ }^{29}$ Ibídem, p. 82.

${ }^{30}$ G. Gusdorf, Condiciones y límites de la autobiografía, [en] Suplementos anthropos, $\mathrm{n}^{\circ} 29$, Barcelona 1991, pp. 9-18.
} 


\section{BIBLIOGRAFÍA}

Chacel, R. (1971), La confesión, Madrid, Edhasa.

Estébanez Calderon D. (1996), Diccionario de términos literarios, Madrid, Alianza Editorial. Gusdorf, G. (1991), Condiciones y limites de la autobiografia, Suplementos Anthropos, $\mathrm{n}^{\circ} 29$, Barcelona.

Lejeune Ph. (1991), El pacto autobiográfico, Suplementos Anthropos, n² 29, Barcelona.

Moliner, M. (1991), Diccionario de uso del español, t. I, Madrid, Gredos.

Olney, J. (1991), Algunas versiones de la memoria / Algunas versiones del "bios»: la ontología de la autobiografía, Suplementos Anthropos, $\mathrm{n}^{\circ} 29$, Barcelona.

Rous se au, J.-J. (1978), Confesiones, Traducción Rafael Urbano, Madrid, Tebas, Colección Autobiografías y Diarios.

San Agustín, (1999). Confesiones, Prólogo, traducción y notas de Pedro Rodríguez Santidrián, Madrid, Alianza Editorial.

Starobinski, J. (1957), Jean-Jacques Rousseau. La transparence et l'obstacle, París, Librarie Plon.

Zambrano, M. (1995), La Confesión: Género literario, Madrid. Siruela, Biblioteca de Ensayo. 